OPEN ACCESS

Edited by:

Chihaya Adachi,

Kyushu University, Japan

Reviewed by:

Przemyslaw Data,

Silesian University of

Technology, Poland

Rafal Czerwieniec,

University of Regensburg, Germany

*Correspondence:

Chi-Ming Che

cmche@hku.hk

Specialty section: This article was submitted to

Organic Chemistry,

a section of the journal

Frontiers in Chemistry

Received: 29 February 2020 Accepted: 23 June 2020

Published: 31 July 2020

Citation:

To W-P, Cheng G, Tong GSM, Zhou D and Che C-M (2020) Recent

Advances in Metal-TADF Emitters and

Their Application in Organic

Light-Emitting Diodes.

Front. Chem. 8:653.

doi: 10.3389/fchem.2020.00653

\section{Recent Advances in Metal-TADF Emitters and Their Application in Organic Light-Emitting Diodes}

\author{
Wai-Pong To ${ }^{1}$, Gang Cheng ${ }^{1,2}$, Glenna So Ming Tong ${ }^{1}$, Dongling Zhou ${ }^{1}$ and \\ Chi-Ming Che ${ }^{1,2 *}$
}

'State Key Laboratory of Synthetic Chemistry, HKU-CAS Joint Laboratory on New Materials, Department of Chemistry, The University of Hong Kong, Hong Kong, China, ${ }^{2}$ HKU Shenzhen Institute of Research and Innovation, Shenzhen, China

In this contribution, recent advances in new classes of efficient metal-TADF complexes, especially those of $A u(I), A u(I I I)$, and $W(V I)$, and their application in OLEDs are reviewed. The high performance (EQE $=25 \%)$ and long device operational lifetime $\left(L T_{95}=5,280 \mathrm{~h}\right)$ achieved in an OLED with tetradentate Au(III) TADF emitter reflect the competitiveness of this class of emitters for use in OLEDs with practical interest. The high EQE of 15.6\% achieved in solution-processed OLED with W(VI) TADF emitter represents an alternative direction toward low-cost light-emitting materials. Finally, the design strategy of metal-TADF emitters and their next-stage development are discussed.

Keywords: TADF, gold, tungsten, palladium, silver, organic light-emitting diode

\section{INTRODUCTION}

Thermally activated delayed fluorescence (TADF) materials have become a promising class of photo-functional materials with potential practical applications most exemplified in the field of organic light-emitting diodes (OLEDs). The majority of TADF materials reported to date are organic compounds having donor and acceptor moieties that give rise to emissive charge transfer (CT) excited states upon light excitation. By carefully positioning the donor(s) and acceptor(s), a small singlet-triplet energy gap $\left(\Delta E\left(\mathrm{~S}_{1}-\mathrm{T}_{1}\right)\right)$ can be achieved, thereby allowing efficient reverse intersystem crossing (RISC) to singlet excited state and TADF to occur at room temperature. While numerous classes of molecular organic TADF materials have been reported, the diversity of metal complexes exhibiting TADF property is very limited. In this article, we discuss the recent advances on metal complexes which display TADF and their application in OLEDs.

\section{RECENT ADVANCES IN METAL-TADF COMPLEXES AND THEIR APPLICATION IN OLEDS}

\section{Metal-TADF Light-Emitting Complexes}

The burgeoning development of emitters for OLEDs started from the fluorescent metal complex 8-hydroxyquinoline aluminum $\left(\mathrm{Alq}_{3}\right)$ (Tang and VanSlyke, 1987). Despite its high luminance, high electron mobility and stability, the efficiency of Alq 3 -based OLED is limited by its fluorescence nature. Theoretically, the upper limit of internal quantum efficiency (IQE) of a fluorescent OLED is about $25 \%$ as only singlet spin states can emit light in fluorescent emitters. In this regard, phosphorescent metal complexes have been attracting much attention considering the $100 \%$ potential IQE in electro-phosphorescence (Baldo et al., 1998; Ma et al., 1998). Typical phosphorescent emitters are heavy metal complexes such as those of $\mathrm{Ru}(\mathrm{II})$, $\operatorname{Ir}(\mathrm{III}), \mathrm{Os}(\mathrm{II})$, and $\mathrm{Pt}(\mathrm{II})$ with emission lifetimes $(\tau)$ ranging 1-100 $\mu$ s due to significant mixing 
between the metal and ligand frontier molecular orbitals and the efficient spin-orbit coupling induced by the heavy metal atom. Because of their high luminescence efficiency and high stability, phosphorescent $\operatorname{Ir}(\mathrm{III})$ complexes have been widely used as emitting dopants in OLED industry (Baldo et al., 1999). Nonetheless, the earth abundance of iridium is the lowest among the metal elements, leading to sustainability concern. An alternative approach to harvest triplet excitons at room temperature is via TADF (Yersin et al., 2011; Uoyama et al., 2012). The key process in TADF is up-conversion from the lowest triplet excited state $\left(T_{1}\right)$ to the lowest singlet excited state $\left(S_{1}\right)$, which is then followed by fluorescence from $S_{1}$ to the singlet ground state $\left(\mathrm{S}_{0}\right)$. Therefore, a delicate trade-off between $\Delta E\left(\mathrm{~S}_{1}-\mathrm{T}_{1}\right)$ and oscillator strength of $S_{0}-S_{1}$ transition is crucial to achieve TADF. Since the reports by Endo et al. (2009), Deaton et al. (2010), and also by Uoyama et al. (2012), a plethora of organic TADF molecules have been reported (Wong and Zysman-Colman, 2017; Yang et al., 2017) but examples of metal-TADF emitters are mostly limited to copper complexes (Czerwieniec et al., 2016; Leitl et al., 2016). Since Cu(I) complexes generally lack thermal and electrochemical stability, efforts have been directed to develop 2nd and 3rd row transition-metal-TADF emitters such as those of $\mathrm{Pd}(\mathrm{II}), \mathrm{Ag}(\mathrm{I}), \mathrm{Au}(\mathrm{I})$, and $\mathrm{Au}(\mathrm{III})$ to meet the stringent requirements of emitters for practical OLEDs (Li G. et al., 2019). Gratifyingly, high external quantum efficiencies (EQEs) of up to 27.5 and $25.0 \%$ have been achieved in OLEDs with $\mathrm{Au}(\mathrm{I})$ and $\mathrm{Au}(\mathrm{III}) \mathrm{TADF}$ emitters, respectively (Di et al., 2017; Zhou et al., 2020), reflecting Au-TADF emitters as an emerging new class of competitive, emissive dopant in OLED industry.

The first report on electroluminescence (EL) of $\mathrm{Cu}$ (I) complex appeared soon after the reports on OLEDs based on $\mathrm{Pt}(\mathrm{II})$ and Os(II) emitters (Ma et al., 1999a,b). A Cu(I) complex could exhibit phosphorescence or TADF depending on its $\Delta E\left(\mathrm{~S}_{1}-\mathrm{T}_{1}\right)$ (Leitl et al., 2014). TADF could take place when the $\Delta E\left(\mathrm{~S}_{1}-\mathrm{T}_{1}\right)$ is comparable to the thermal energy $k_{\mathrm{B}} T$ that enables a dynamic equilibrium between $S_{1}$ and $T_{1}$. Several high-performance OLEDs based on $\mathrm{Cu}(\mathrm{I})$ complexes have been reported (Zhang et al., 2012, 2016; Cheng et al., 2015; Osawa et al., 2015; Volz et al., 2015; So et al., 2017; Hamze et al., 2019; Shi et al., 2019). For instance, Bräse, So, Baumann and co-workers reported EQEs of up to 23\% for yellow-emitting OLEDs with an NHetPHOS-Cu(I) complex (NHetPHOS refers to a ligand having $\mathrm{N}$-heterocycle and phosphine) as the emitter (Volz et al., 2015). Thompson reported a class of two-coordinate $\mathrm{Cu}(\mathrm{I})$ carbene amide complexes exhibiting photoluminescent quantum yields (PLQYs) up to 1.0 with $\tau$ of $1-2 \mu \mathrm{s}$. EQEs of OLEDs fabricated with these emitters reached $19.4 \%$ (Shi et al., 2019). Since the development of TADF Cu(I) complexes has been well-reviewed (Czerwieniec et al., 2016; Yersin et al., 2017; Liu et al., 2018; Li G. et al., 2019), we will focus in this contribution on recent advances of efficient TADF metal complexes other than $\mathrm{Cu}(\mathrm{I})$ complexes that have been applied as emitting dopants in OLEDs.

\section{Silver TADF Complexes and Their Application in OLEDs}

Several examples of $\mathrm{Ag}(\mathrm{I}) \mathrm{TADF}$ emitters have been reported recently. $\mathrm{Lu}$ discovered bis-bidentate tetraphosphine bridged binuclear Ag(I) halide complexes exhibiting TADF with PLQYs up to 0.98 and lifetime of 2.5-3.0 $\mu$ s (Chen et al., 2016). Yersin reported a series of $\mathrm{Ag}(\mathrm{I})$ complexes supported by 1,10 phenanthroline and bis(diphenylphosphine)-nido-carborane (e.g., Ag-1, Figure 1) with PLQYs up to 1.0 and $\tau$ ranging 1.4-2.8 Ms (Shafikov et al., 2017a,b). Replacing 1,10-phenanthroline with a bridging tetraphosphine ligand afforded a binuclear Ag(I) TADF complex Ag-2 with PLQY of 0.70 and $\tau$ of $1.9 \mu$ s (Shafikov et al., 2018). A Ag(I) carbene amide complex also exhibits TADF with PLQY of 0.74 and $\tau$ of 460 ns in degassed toluene. OLEDs fabricated with this emitter showed EQEs up to $13.7 \%$ (Romanov et al., 2018).

\section{Gold TADF Complexes and Their Application in OLEDs}

Gold is an attractive candidate for developing OLED emitters attributable to the high thermal stability endowed by strong gold-ligand bonds and its relatively high abundance among other noble metals in Earth's crust. Due to the electrophilicity/relatively high reduction potential of $\mathrm{Au}(\mathrm{III}), \mathrm{Au}(\mathrm{III})$ complexes often display ligand-centered emission having minute metal contribution. This results in small radiative decay rate constants $\left(k_{\mathrm{r}}\right)$ of $10^{2}-10^{3} \mathrm{~s}^{-1}$ and hence long $\tau$ (usually $>10 \mu \mathrm{s}$ ), longer than those of typical $\operatorname{Ir}($ III) and $\mathrm{Pt}(\mathrm{II})$ complexes by one or two orders of magnitude (Zhou et al., 2019). As long emission lifetimes would cause severe efficiency roll-off in OLEDs (Cheng et al., 2014), only a few of them could achieve decent EQE and low efficiency roll-off at the same time. Notably, the study on $\mathrm{Au}(\mathrm{I})$-OLEDs was even rarer than those of $\mathrm{Au}(\mathrm{III})$-OLEDs (Ma et al., 1999b,c). In this regard, the recent development of TADF gold complexes has made a remarkable turnaround. Linnolahti, Bochmann, Credgington and co-workers reported a series of 2-coordinate carbene-Au(I)-amides (CMAs) that consist of a cyclic (alkyl)(amino)carbene (CAAC) connected via $\mathrm{Au}(\mathrm{I})$ to a carbazolate or diphenylamide (Di et al., 2017). Computations revealed that $\Delta E\left(\mathrm{~S}_{1}-\mathrm{T}_{1}\right)$ of CMA-1 remains small $\left(<800 \mathrm{~cm}^{-1}\right)$ along the torsional coordinate, even at the coplanar conformation which has fluorescence rate of the order $10^{7} \mathrm{~s}^{-1}$, thus leading to a fast equilibration of the $\mathrm{S}_{1}$ and $\mathrm{T}_{1}$ excited states and a large $k_{\mathrm{r}}$ of $2.4 \times 10^{6} \mathrm{~s}^{-1}$, PLQY of 0.83 and short $\tau$ of $\sim 350 \mathrm{~ns}$ in neat film at $300 \mathrm{~K}$ (Föller and Marian, 2017; Conaghan et al., 2018). A maximum EQE of $26.3 \%$ was achieved in solution-processed OLEDs with CMA1 as the emitter and high EQE of $24.5 \%$ was maintained at a luminance of $1,000 \mathrm{~cd} \mathrm{~m}^{-2}$. Nonetheless, there has been no report on the operational lifetimes of the aforementioned $\mathrm{Au}(\mathrm{I}) / \mathrm{Cu}(\mathrm{I}) / \mathrm{Ag}(\mathrm{I})-\mathrm{TADF}$ OLEDs. In 2017, Che and co-workers identified TADF as the emission origin in several pincer Au(III) aryl emitters (To et al., 2017). The presence of diarylamino group on the monodentate aryl ligand, and its twisted geometry with respect to the cyclometalating ligand, results in TADF in Au-1 (Figure 1). Based on variable temperature-emission lifetime measurements and DFT calculations, a $\Delta E\left(\mathrm{~S}_{1}-\mathrm{T}_{1}\right)$ of $318 \mathrm{~cm}^{-1}$ was estimated for this complex. With short $\tau$ of $0.72 \mu \mathrm{s}$ and high PLQY of 0.84 in room temperature, solution-processed OLEDs with Au-1 showed EQE and luminance of up to $23.8 \%$ and $57,340 \mathrm{~cd} \mathrm{~m}^{-2}$, respectively. It is noted that both devices based on the $\mathrm{Au}(\mathrm{I})$ complex CMA1 and the Au(III) complex Au-1 were fabricated by solution-processed technique. In this regard, 

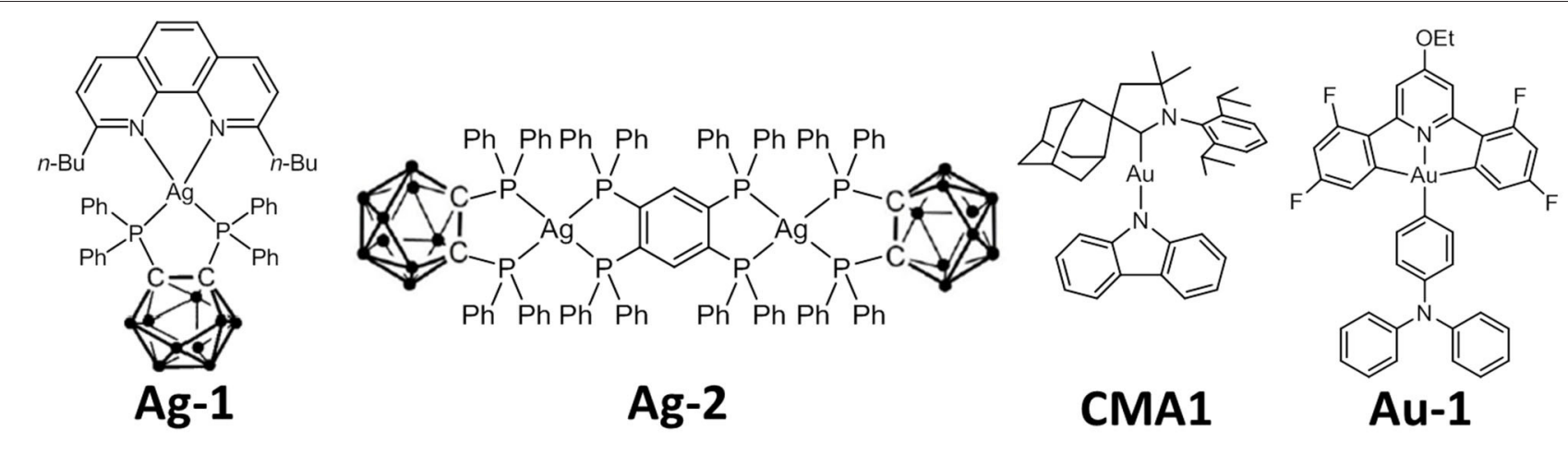

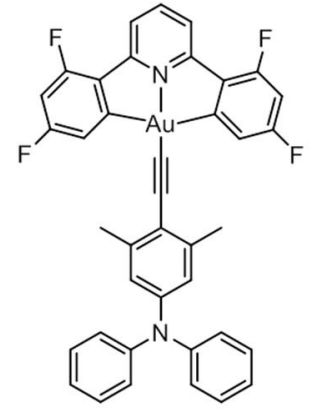

Au-2

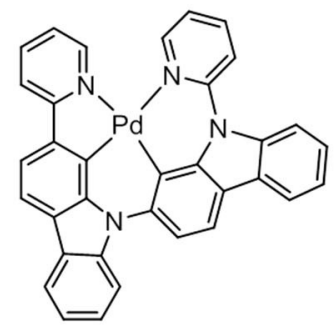

PdN3N
$\mathrm{Ag}-2$

CMA1
Au-1<smiles>CC(C)c1ccccc1C(C)(I)[Al]P(c1ccccc1C(C)C)(c1ccccc1C(C)C)(c1ccccc1C(C)C)c1ccccc1C(C)C</smiles>

Au-3

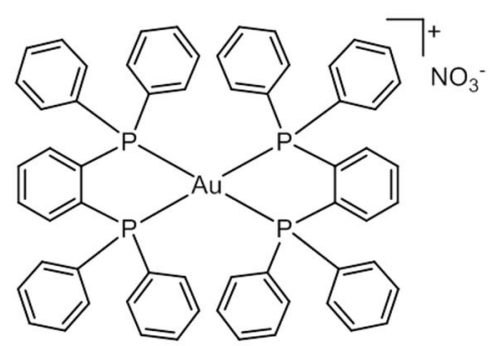

Au-4

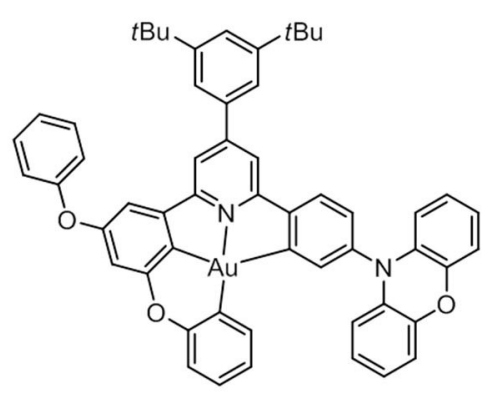

Au-5

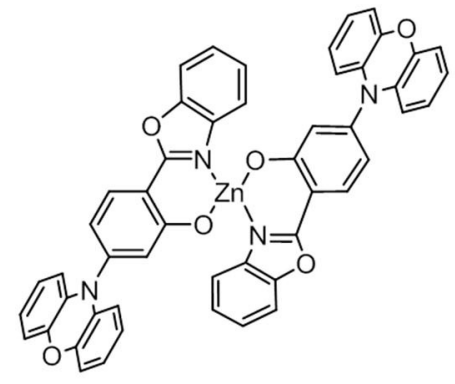

$\mathrm{Zn-1}$

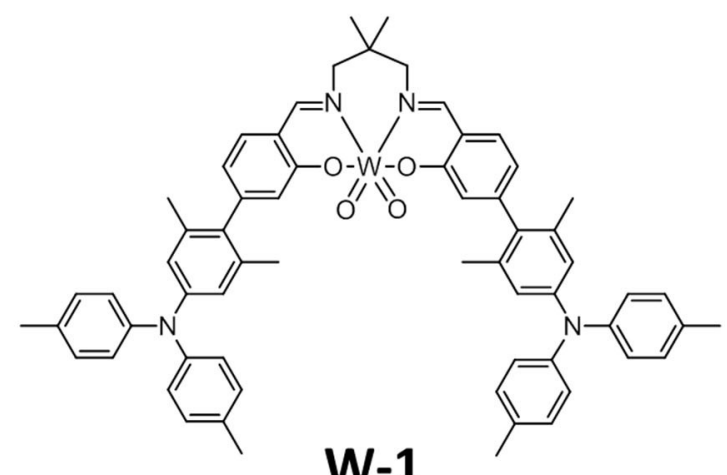

W-1

FIGURE 1 | Chemical structures of selected metal-TADF complexes.

studies on EL of these gold complexes in vacuum-deposited devices were undertaken to determine if they have potential application in practical OLEDs. High maximum EQEs of 26.9 and $23.4 \%$ were achieved in vacuum-deposited OLEDs with $\mathrm{Au}(\mathrm{I})$ complex CMA1 (Conaghan et al., 2018) and pincer Au(III) alkynyl complex Au-2 (Figure 1; Zhou et al., 2019), respectively. Despite the slightly lower efficiency, the device lifetime ( $\left.\mathrm{LT}_{95}\right)$ of the latter has been measured to be $\sim 500 \mathrm{~h}$ at an initial luminance of $100 \mathrm{~cd} \mathrm{~m}^{-2}$, which is at least comparable to that of pincer $\mathrm{Au}(\mathrm{III})$ complex bearing deprotonated carbazole as auxiliary ligand reported by Li L.-K. et al. (2019). The improved thermal stability of $\mathrm{Au}(\mathrm{III})$ alkynyl complexes compared to the aryl ones is attributed to the stronger $\mathrm{Au}(\mathrm{III})-\mathrm{C}_{\mathrm{sp}}$ bond in the alkynyl counterparts. $\mathrm{Au}(\mathrm{I})$ complexes with diphosphine ligand(s) have also been reported to display TADF (Osawa et al., 2018). The crystalline solid of $\mathrm{Au}(\mathrm{I})$ diphosphine iodide (Au-3) displayed yellow photoluminescence with PLQY of 0.92 and lifetime of 9.0 $\mu$ s. Its emission shows a red-shift of $20 \mathrm{~nm}$, a decrease in PLQY to 0.74 and an increase of lifetime to $77 \mu \mathrm{s}$, corresponding to a reduction in $k_{\mathrm{r}}$ from $1.0 \times 10^{5} \mathrm{~s}^{-1}$ to $9.6 \times 10^{3} \mathrm{~s}^{-1}$ upon cooling from 293 to $77 \mathrm{~K}$. Au(I) bis-diphosphine complex Au-4 exhibits a high PLQY of 0.95 but with much shorter lifetime of $3.8 \mu \mathrm{s}$. The $\Delta E\left(\mathrm{~S}_{1}-\mathrm{T}_{1}\right)$ of $\mathbf{A u}-\mathbf{3}$ and $\mathbf{A u}-\mathbf{4}$ were estimated to be 870 and $620 \mathrm{~cm}^{-1}$, respectively.

\section{Tetradentate Metal-TADF Emitters and Their Application in OLEDs}

The aforementioned TADF $\mathrm{Au}(\mathrm{I})$ and $\mathrm{Au}(\mathrm{III})$ complexes were prepared by using two ligands. Since the stability of metal complexes could be increased by employing chelating ligands of higher denticity, the employment of tetradentate ligand with C-donor atom(s) is envisaged to improve the thermal 
TABLE 1 | Key performances of selected metal-TADF complexes.

\begin{tabular}{|c|c|c|c|c|c|c|}
\hline \multirow[t]{2}{*}{ Complex } & \multirow[t]{2}{*}{ Fabrication method } & \multicolumn{2}{|c|}{ EQE (\%) } & \multirow[t]{2}{*}{$L^{d}\left(c d m^{-2}\right)$} & \multirow[t]{2}{*}{$\operatorname{CIE}^{\mathrm{e}}(x, y)$} & \multirow[t]{2}{*}{ Lifetime $^{f}$ (h) } \\
\hline & & Max. & At $1,000 \mathrm{~cd} \mathrm{~m}^{-2}$ & & & \\
\hline \multirow[t]{2}{*}{ CMA1 } & $\mathrm{SP}^{\mathrm{a}}$ & 26.3 & 25.2 & 44,700 & $0.26,0.49$ & n. a. \\
\hline & $V^{b}$ & 26.9 & 24.9 & 35,400 & $0.24,0.42$ & n. a. \\
\hline$A u-1$ & $\mathrm{SP}^{\mathrm{a}}$ & 23.8 & 16.5 & 33,740 & $0.27,0.51$ & n. a. \\
\hline Au-2 & $V^{b}$ & 23.4 & 22.1 & 70,300 & $0.40,0.55$ & 500 \\
\hline Au-5 & $V^{b}$ & 25.0 & 22.0 & 22,700 & $0.43,0.54$ & 5,280 \\
\hline PdN3N & $V^{b}$ & 20.9 & $7.0^{c}$ & n. a. & $0.30,0.61$ & $6,000^{c}$ \\
\hline $\mathrm{Zn}-1$ & $V^{b}$ & 19.6 & n. a. & n. a. & n. a. & n. a. \\
\hline$W-1$ & $\mathrm{SP}^{\mathrm{a}}$ & 15.6 & 9.7 & 16,890 & $0.49,0.49$ & n. a. \\
\hline
\end{tabular}

a Solution process; ${ }^{b}$ Vacuum deposition; ${ }^{c}$ Estimated from the original reference; ${ }^{d}$ Maximum luminance; ${ }^{e} \mathrm{CIE}$ coordinates; ${ }^{f} L T_{95}$ at $L_{0}=100 \mathrm{~cd} \mathrm{~m}^{-2}$.

stability and to restrict excited-state structural distortion of the resultant complex as exemplified in tetradentate $\mathrm{Pt}(\mathrm{II})$ and Pd(II) complexes (Vezzu et al., 2010; Cheng et al., 2013; Chow et al., 2016). Furthermore, it was suggested that an increase in the structural rigidity of emitters could suppress structural deformation upon $\mathrm{S}_{1}-\mathrm{T}_{1}$ transformation, which reduces $\Delta E\left(\mathrm{~S}_{1}\right.$ $\mathrm{T}_{1}$ ) and leads to efficient TADF (Saigo et al., 2019). Therefore, the development of TADF $\mathrm{Au}(\mathrm{III})$ complexes supported by trianionic tetradentate ligands would be an appealing direction toward practical Au-OLEDs. A class of $\mathrm{Au}$ (III) complexes supported by N-bridged tetradentate ligand prepared by postmodification was reported by Wong et al. (2017). These complexes exhibit photoluminescence from triplet intraligand charge-transfer (ILCT) excited states with PLQY of up to 0.78 in thin films. Solution-processed OLEDs fabricated with these emitters showed EQE of up to $11.1 \%$. Che and co-workers developed new strategies for synthesizing tetradentate $\mathrm{Au}(\mathrm{III})$ complexes with O-bridged/spiro-arranged $\mathrm{C}^{\wedge} \mathrm{C}^{\wedge} \mathrm{N}^{\wedge} \mathrm{C}$ ligand by microwave induced C-H activation (Zhou et al., 2020). By rationally varying the substituent(s) on the ligand, the emissive excited states of the $\mathrm{Au}(\mathrm{III})$ emitters are changed from triplet intraligand ( $\left.{ }^{3} \mathrm{IL}\right)$ excited states with $k_{\mathrm{r}}$ of $\sim 10^{3} \mathrm{~s}^{-1}$, to TADF from ILCT excited states. These Au(III) TADF emitters show high thermal stability and PLQYs of up to 0.94 and $\tau$ down to 0.62 $\mu \mathrm{s}$ in degassed toluene. A vacuum-deposited OLED with Au-5 as the emissive dopant showed maximum EQE of $25 \%$ and the EQE value maintained at $22 \%$ at a luminance of $1,000 \mathrm{~cd} \mathrm{~m}^{-2}$. Significantly, as listed in Table 1, at an initial luminance of $100 \mathrm{~cd}$ $\mathrm{m}^{-2}$, this device showed a much longer lifetime $\mathrm{LT}_{95}$ of $5,280 \mathrm{~h}$. This value is at least 10 -fold longer than those recorded with pincer Au(III) emitters (Li L.-K. et al., 2019; Zhou et al., 2019). This result highlights the advantage of using tetradentate ligand in the preparation of robust $\mathrm{Au}$ (III) TADF emitters for practical use. It also showcases tetradentate $\mathrm{Au}$ (III) TADF complexes as competitive candidate in OLED industry.

Tetradentate ligand has also been used in preparing stable, luminescent $\mathrm{Pd}(\mathrm{II})$ complexes. $\mathrm{Li}$ and co-workers reported a tetradentate $\mathrm{Pd}(\mathrm{II})$ complex, $\mathbf{P d N} 3 \mathbf{N}$, which contains a $\mathrm{C}^{\wedge} \mathrm{N}$ cyclometalating moiety composed of 2-pyridyl-carbazole, where the $T_{1}$ is localized, and also a donor-acceptor moiety of carbazole-carbazoyl-pyridine (Figure 1, Zhu et al., 2015).
PdN3N exhibited both phosphorescence and TADF at room temperature with PLQY of 0.72. A maximum EQE of 20.9\% and operational lifetime $\mathrm{LT}_{90}$ of $170 \mathrm{~h}$ at an initial luminance of $1,697 \mathrm{~cd} \mathrm{~m}^{-2}$ were achieved in the OLED with PdN3N. Nonetheless, the EQE of this device dropped to $\sim 7.0 \%$ at a luminance of $1,000 \mathrm{~cd} \mathrm{~m}^{-2}$. Such severe efficiency roll-off is a result of the long $\tau$ of $>100 \mu$ s for PdN3N, which limits the application of this kind of $\mathrm{Pd}(\mathrm{II})$ complexes in practical OLEDs. In addition, the color purity of the Pd-OLED is not good enough because of the wide EL spectrum resulting from dual emission from both phosphorescence and TADF.

\section{Inexpensive Metal-TADF Complexes and Their Application in OLEDs}

The low earth abundance of noble metals (e.g., iridium, platinum) has stimulated a great interest to invent new classes of luminescent materials based on inexpensive, earth-abundant metals (Bizzarri et al., 2018; Wenger, 2018). Besides Cu(I) complexes, more examples of inexpensive metal-TADF emitters have been reported. Adachi and co-workers synthesized TADF materials based on zinc, magnesium and lithium having ILCT transition (Sakai et al., 2015). Zn-1 (Figure 1) was the most efficient emitter among these complexes. The EQE of vacuumdeposited OLEDs based on Zn-1 was up to nearly $20 \%$. By employing terphenyl having carboxyl and diphenylamine groups as linkers, Adachi, Kabe and co-workers constructed a zirconium-based metal-organic framework exhibiting green TADF with PLQY of 0.30 under vacuum (Mieno et al., 2018).

Tungsten is another appealing candidate for developing luminescent metal-based materials because of its large spin-orbit coupling constant $\left(2,433 \mathrm{~cm}^{-1}\right)$ which facilitates intersystem crossing and significantly higher earth abundance than noble metals. Nonetheless, examples of air-stable tungsten complexes displaying strong photoluminescence are rare with the recent report on W(VI) cis-dioxo Schiff base and quinolinolate complexes by Yeung et al. (2017). One of these complexes exhibit PLQYs of up to 0.22 in thin film and was used as emitter to realize the first tungsten-OLED, though the maximum EQE achieved was only $4.79 \%$. While the proof of principle has been demonstrated, the low PLQY and inferior performance data suggested that significant improvement in the photo-luminescent 
properties of luminescent W(VI) complexes is needed if the latter are to be used for practical applications. With a view to designing $\mathrm{W}(\mathrm{VI})$ complexes with competitive luminescent properties for OLED application, it is conceived that installation of diarylamino group(s) on the Schiff base ligand may change the emission origin to TADF (To et al., 2017; Zhou et al., 2019), thereby boosting $k_{\mathrm{r}}$ and improving PLQY. Che and co-workers described the first example of tungsten TADF emitter in 2019 (Chan et al., 2019). This study has demonstrated that the incorporation of diarylamino donor groups into the ligand scaffold changes the emissive excited state from long-lived ${ }^{3} \mathrm{IL}$ ones to TADF arising from ILCT excited state, which effectively boosts PLQY of W(VI) Schiff base complex to 0.84 in thin film. The estimated $k_{\mathrm{r}}$ of W-1 (Figure 1) is $4.2 \times 10^{5} \mathrm{~s}^{-1}$, which is at least 100 fold larger than that of analogous W(VI) complexes without diarylamino group. DFT calculations revealed that the subtle change on the twisted angle between the diarylamino substituent and the phenolic moiety is the key that influences the excited state dynamics and modulates the singlet-triplet energy separation, leading to efficient TADF in complex W-1. Solution-processed OLEDs fabricated with W-1 showed EQEs of up to $15.6 \%$, which is a significant improvement compared to the previous work $\left(\mathrm{EQE}_{\max }=4.79 \%\right)$.

\section{DISCUSSION}

The variety and design strategy of metal-TADF emitters remain considerably scarce despite the recent discoveries on $\mathrm{Au}(\mathrm{I})$, $\mathrm{Au}(\mathrm{III}), \mathrm{Ag}(\mathrm{I})$, and Pd(II) TADF emitters. Summarizing from the recent findings, metal-TADF emitters are generally realized in complexes that are composed of electrophilic metal ion, such as those of $\mathrm{Au}(\mathrm{III}), \mathrm{W}(\mathrm{VI})$, and $\mathrm{Pd}(\mathrm{II})$. In these complexes, the emission origin is changed from phosphorescence $\left({ }^{3} \mathrm{LC}\right)$ to TADF by adding donor groups to generate LLCT/ILCT excited states. The originally small $k_{\mathrm{r}}$ of these complexes allows an easy identification of whether TADF is operative because a 100fold (or even more) increase in $k_{\mathrm{r}}$ would be observed when TADF takes place, as exemplified in $\mathrm{Au}(\mathrm{III})$ and $\mathrm{W}(\mathrm{VI}) \mathrm{TADF}$ emitters. This finding is similar to that of organic compounds which are known to show long-lived phosphorescence $\left(k_{\mathrm{r}}<\right.$ $\left.100 \mathrm{~s}^{-1}\right)$. By incorporating donor-acceptor pair, TADF can be

\section{REFERENCES}

Baldo, M. A., Lamansky, S., Burrows, P. E., Thompson, M. E., and Forrest, S. R. (1999). Very high- efficiency green organic light-emitting devices based on electrophosphorescence. Appl. Phys. Lett. 75, 4-6. doi: 10.1063/1.124258

Baldo, M. A., O’Brien, D. F., You, Y., Shoustikov, A., Sibley, S., Thompson, M. E., et al. (1998). Highly efficient phosphorescent emission from organic electroluminescent devices. Nature 395, 151-154. doi: 10.1038/25954

Bizzarri, C., Spuling, E., Knoll, D. M., Volz, D., and Bräse, S. (2018). Sustainable metal complexes for organic light-emitting diodes (OLEDs). Coord. Chem. Rev. 373, 49-82. doi: 10.1016/j.ccr.2017.09.011

Chan, K.-T., Lam, T.-L., Yu, D., Du, L., Phillips, D. L., Kwong, C.-L., et al. (2019). Strongly luminescent tungsten emitters with emission quantum yields of up to 84\%: TADF and high-efficiency molecular tungsten OLEDs. Angew. Chem. Int. Ed. 58, 14896-14900. doi: 10.1002/anie.201906698 observed and the $k_{\mathrm{r}}$ of organic compounds can be increased significantly. Accordingly, it may be a challenge to realize TADF in $\mathrm{Pt}(\mathrm{II})$ and $\mathrm{Ir}(\mathrm{III})$ complexes due to their large phosphorescent $k_{\mathrm{r}}$ which facilitates efficient radiative decay via triplet excited state. Another consideration is that as the $k_{\mathrm{r}}$ of phosphorescent $\mathrm{Pt}$ (II) and $\operatorname{Ir}(\mathrm{III})$ are already large $\left(10^{5}-10^{6} \mathrm{~s}^{-1}\right)$, switching the emission origin to TADF may not lead to a drastic increase in $k_{\mathrm{r}}$ and this renders the identification of whether TADF is occurring in these complexes highly challenging.

Compared to pure organic TADF emitters, $\tau$ of triplet excited states of metal-TADF complexes is much shorter, which could be advantageous for the operational stability of OLEDs based on metal-TADF emitters. Furthermore, with the use of rigid tetradentate ligands, a drastic improvement in terms of efficiency and device stability could be realized as that observed for tetradentate $\mathrm{Au}$ (III) TADF emitters. This finding calls for a more stringent ligand design for practical metal-TADF emitters in addition to pursuing high PLQY and short $\tau$.

Besides, the questionable practicability of $\mathrm{Cu}(\mathrm{I})$ complexes in OLEDs triggers the investigation on TADF emitters based on other inexpensive metals. Although TADF $\mathrm{Zn}(\mathrm{II})$ and W(VI) complexes have shown high PLQY and EL efficiency, the improvement of operational lifetime of devices based on these complexes remains a formidable challenge. The deployment of robust and rigid ligands that would induce the occurrence of TADF could be the key to increase the practical potential of emitters based on earth-abundant metals.

\section{AUTHOR CONTRIBUTIONS}

All authors contributed to the writing of the manuscript.

\section{FUNDING}

This work was supported by the Major Program of Guangdong Basic and Applied Research (2019B030302009), Science, Technology and Innovation Commission of Shenzhen Municipality (JCYJ20170818141858021 and JCYJ20180508162429786), Hong Kong Research Grants Council (HKU 17330416), and CAS-Croucher Funding Scheme for Joint Laboratories. 
solution-processed monochromic and white organic light-emitting devices. Chem. Sci. 6, 4623-4635. doi: 10.1039/C4SC03161J

Chow, P.-K., Cheng, G., Tong, G. S. M., Ma, C., Kwok, W.-M., Ang, W.-H., et al. (2016). Highly luminescent palladium(II) complexes with sub-millisecond blue to green phosphorescent excited states. Photocatalysis and highly efficient PSF-OLEDs. Chem. Sci. 7, 6083-6098. doi: 10.1039/C6SC00462H

Conaghan, P. J., Menke, S. M., Romanov, A. S., Jones, S. T. E., Pearson, A. J., Evans, E. W., et al. (2018). Efficient vacuum-processed light-emitting diodes based on carbene-metal-amides. Adv. Mater. 30:1802285. doi: 10.1002/adma.201802285

Czerwieniec, R., Leitl, M. J., Homeier, H. H. H., and Yersin, H. (2016). $\mathrm{Cu}(\mathrm{I})$ complexes-thermally activated delayed fluorescence. Photophysical approach and material design. Coord. Chem. Rev. 325, 2-28. doi: 10.1016/j.ccr.2016.06.016

Deaton, J. C., Switalski, S. C., Kondakov, D. Y., Young, R. H., Pawlik, T. D., Giesen, D. J., et al. (2010). E-type delayed fluorescence of a phosphine-supported $\mathrm{Cu}_{2}\left(\mu-\mathrm{NAr}_{2}\right)_{2}$ diamond core: harvesting singlet and triplet excitons in OLEDs. J. Am. Chem. Soc. 132, 9499-9508. doi: 10.1021/ja1004575

Di, D., Romanov, A. S., Yang, L., Richter, J. M., Rivett, J. P. H., Jones, S., et al. (2017). High-performance light-emitting diodes based on carbene-metalamides. Science 356, 159-163. doi: 10.1126/science.aah4345

Endo, A., Ogasawara, M., Takahashi, A., Yokoyama, D., Kato, Y., and Adachi, C. (2009). Thermally activated delayed fluorescence from $\mathrm{Sn}^{4+}$ Porphyrin complexes and their application to organic light emitting diodesA novel mechanism for electroluminescence. Adv. Mater. 21, 4802-4806. doi: 10.1002/adma.200900983

Föller, J., and Marian, C. M. (2017). Rotationally assisted spin-state inversion in carbene-metal-amides is an artifact. J. Phys. Chem. Lett. 8, 5643-5647. doi: 10.1021/acs.jpclett.7b02701

Hamze, R., Peltier, J. L., Sylvinson, D., Jung, M., Cardenasm, J., Haiges, R., et al. (2019). Eliminating nonradiative decay in $\mathrm{Cu}(\mathrm{I})$ emitters: $>99 \%$ quantum efficiency and microsecond lifetime. Science, 363, 601-606. doi: $10.1126 /$ science.aav2865

Leitl, M. J., Krylova, V. A., Djurovich, P. I., Thompson, M. E., and Yersin, H. (2014). Phosphorescence versus thermally activated delayed fluorescence. Controlling singlet-triplet splitting in brightly emitting and sublimable $\mathrm{Cu}(\mathrm{I})$ compounds. J. Am. Chem. Soc. 136, 16032-16038. doi: 10.1021/ja508155x

Leitl, M. J., Zink, D. M., Schinabeck, A., Baumann, T., Volz, D., and Yersin, H. (2016). Copper(I) complexes for thermally activated delayed fluorescence: from photophysical to device properties. Top. Curr. Chem. 374:25. doi: 10.1007/s41061-016-0019-1

Li, G., Zhu, Z.-Q., Chen, Q., and Li, J. (2019). Metal complex based delayed fluorescence materials. Org. Electron. 69, 135-152. doi: 10.1016/j.orgel.2019.02.022

Li, L.-K., Tang, M.-C., Lai, S.-L., Ng, M., Kwok, W.-K., Chan, M.-Y., et al. (2019). Strategies towards rational design of gold(III) complexes for highperformance organic light-emitting devices. Nat. Photonics 13, 185-191. doi: 10.1038/s41566-018-0332-z

Liu, Y., Yiu, S.-C., Ho, C.-L., and Wong, W.-Y. (2018). Recent advances in copper complexes for electrical/light energy conversion. Coord. Chem. Rev. 375, 514-557. doi: 10.1016/j.ccr.2018.05.010

Ma, Y., Chan, W.-H., Zhou, X.-M., and Che, C.-M. (1999a). Light-emitting diode device from a luminescent organocopper(I) compound. New J. Chem. 23, 263-265. doi: 10.1039/a808763f

Ma, Y., Che, C.-M., Chao, H.-Y., Zhou, X., Chan, W.-H., and Shen, J. (1999b). High luminescence gold(I) and copper(I) complexes with a triplet excited state for use in light-emitting diodes. Adv. Mater. 11, 852-857. doi: 10.1002/(SICI)1521-4095(199907)11:10<852::AID-ADMA852>3.0.CO;2-R

Ma, Y., Zhang, H., Shen, J., and Che, C.-M. (1998). Electroluminescence from triplet metal-ligand charge-transfer excited state of transition metal complexes. Synth. Met. 94, 245-248. doi: 10.1016/S0379-6779(97)04166-0

Ma, Y., Zhou, X., Shen, J., Chao, H.-Y., and Che, C.-M. (1999c). Triplet luminescent dinuclear-gold(I) complex-based light-emitting diodes with low turn-on voltage. App. Phys. Lett. 74, 1361-1363. doi: 10.1063/1.123550

Mieno, H., Kabe, R., Allendorf, M. D., and Adachi, C. (2018). Thermally activated delayed fluorescence of $\mathrm{Zr}$-based metal-organic framework. Chem. Commun. 54, 631-634. doi: 10.1039/C7CC08595H

Osawa, M., Aino, M.-A., Nagakura, T., Hoshino, M., Tanaka, Y., and Akita, M. (2018). Near-unity thermally activated delayed fluorescence efficiency in three- and four-coordinate $\mathrm{Au}(\mathrm{I})$ complexes with diphosphine ligands. Dalton Trans. 47, 8229-8239. doi: 10.1039/C8DT01097H

Osawa, M., Hoshino, M., Hashimoto, M., Kawata, I., Igawa, S., and Yashima, M. (2015). Application of three-coordinate copper(I) complexes with halide ligands in organic light-emitting diodes that exhibit delayed fluorescence. Dalton Trans. 44, 8369-8378. doi: 10.1039/C4DT02853H

Romanov, A. S., Jones, S. T. E., Yang, L., Conaghan, P. J., Di, D., Linnolahti, M., et al. (2018). Mononuclear silver complexes for efficient solution and vacuumprocessed OLEDs. Adv. Opt. Mater. 6:1801347. doi: 10.1002/adom.201801347

Saigo, M., Miyata, K., Tanaka, S., Nakanotani, H., Adachi, C., and Onda, K. (2019). Suppression of structural change upon $S_{1}-T_{1}$ conversion assists the thermally activated delayed fluorescence process in carbazole-benzonitrile derivatives. J. Phys. Chem. Lett. 10, 2475-2480. doi: 10.1021/acs.jpclett.9b00810

Sakai, Y., Sagara, Y., Nomura, H., Nakamura, N., Suzuki, Y., Miyazakiae, H., et al. (2015). Zinc complexes exhibiting highly efficient thermally activated delayed fluorescence and their application to organic light-emitting diodes. Chem. Commun. 51, 3181-3184. doi: 10.1039/C4CC09403D

Shafikov, M. Z., Suleymanova, A. F., Czerwieniec, R., and Yersin, H. (2017a). Design strategy for $\mathrm{Ag}(\mathrm{I})$-based thermally activated delayed fluorescence reaching an efficiency breakthrough. Chem. Mater. 29, 1708-1715. doi: 10.1021/acs.chemmater.6b05175

Shafikov, M. Z., Suleymanova, A. F., Czerwieniec, R., and Yersin, H. (2017b). Thermally activated delayed fluorescence from $\mathrm{Ag}(\mathrm{I})$ complexes: a route to $100 \%$ quantum yield at unprecedentedly short decay time. Inorg. Chem. 56, 13274-13285. doi: 10.1021/acs.inorgchem.7b02002

Shafikov, M. Z., Suleymanova, A. F., Schinabeck, A., and Yersin, H. (2018). Dinuclear $\operatorname{Ag}(\mathrm{I})$ complex designed for highly efficient thermally activated delayed fluorescence. J. Phys. Chem. Lett. 9, 702-709. doi: 10.1021/acs.jpclett.7b03160

Shi, S., Jung, M. C., Coburn, C., Tadle, A., Sylvinson, D. M. R., Djurovich, P. I., et al. (2019). Highly efficient photo- and electroluminescence from two-coordinate $\mathrm{Cu}(\mathrm{I})$ complexes featuring nonconventional N-heterocyclic carbenes. J. Am. Chem. Soc. 141, 3576-3588. doi: 10.1021/jacs.8b12397

So, G. K.-M., Cheng, G., Wang, J., Chang, X., Kwok, C.-C., Zhang, H., et al. (2017). Efficient color-tunable copper(I) complexes and their applications in solutionprocessed organic light-emitting diodes. Chem. Asian J. 12, 1490-1498. doi: 10.1002/asia.201700081

Tang, C. W., and VanSlyke, S. A. (1987). Organic electroluminescent diodes. Appl. Phys. Lett. 51, 913-915. doi: 10.1063/1.98799

To, W.-P., Zhou, D., Tong, G. S. M., Cheng, G., Yang, C., and Che, C.-M. (2017). Highly luminescent pincer gold(III) aryl emitters: thermally activated delayed fluorescence and solution-processed OLEDs. Angew. Chem. Int. Ed. 129, 14036-14041. doi: 10.1002/anie.201707193

Uoyama, H., Goushi, K., Shizu, K., Nomura, H., and Adachi, C. (2012). Highly efficient organic light-emitting diodes from delayed fluorescence. Nature 492, 234-238. doi: 10.1038/nature11687

Vezzu, D. A. K., Deaton, J. C., Jones, J. S., Bartolotti, L., Harris, C. F., Marchetti, A. P., et al. (2010). Highly luminescent tetradentate bis-cyclometalated platinum complexes: design, synthesis, structure, photophysics, and electroluminescence application. Inorg. Chem. 49, 5107-5119. doi: 10.1021/ic10 02226

Volz, D., Chen, Y., Wallesch, M., Liu, R., Fléchon, C., Zink, D. M., et al. (2015). Bridging the efficiency gap: fully bridged dinuclear $\mathrm{Cu}(\mathrm{I})$-complexes for singlet harvesting in high-efficiency OLEDs. Adv. Mater. 27, 2538-2543. doi: 10.1002/adma.201405897

Wenger, O. S. (2018). Photoactive complexes with earth-abundant metals. J. Am. Chem. Soc. 140, 13522-13533. doi: 10.1021/jacs.8b08822

Wong, B. Y.-W., Wong, H.-L., Wong, Y.-C., Chan, M.-Y., and Yam, V. W.W. (2017). Versatile synthesis of luminescent tetradentate cyclometalated alkynylgold(III) complexes and their application in solution-processable organic light-emitting devices. Angew. Chem. Int. Ed. 56, 302-305. doi: $10.1002 /$ anie. 201607816

Wong, M. Y., and Zysman-Colman, E. (2017). Purely organic thermally activated delayed fluorescence materials for organic light-emitting diodes. Adv. Mater. 29:1605444. doi: 10.1002/adma.201605444

Yang, Z., Mao, Z., Xie, Z., Zhang, Y., Liu, S., Zhao, J., et al. (2017). Recent advances in organic thermally activated delayed fluorescence materials. Chem. Soc. Rev. 46, 915-1016. doi: 10.1039/C6CS00368K 
Yersin, H., Czerwieniec, R., Shafikov, M. Z., and Suleymanova, A. F. (2017). TADF material design: photophysical background and studies focusing on $\mathrm{Cu}^{\mathrm{I}}$ and $\mathrm{Ag}^{\mathrm{I}}$ complexes. ChemPhysChem 18, 3508-3535. doi: 10.1002/cphc.201700872

Yersin, H., Rausch, A. F., Czerwieniec, R., Hofbeck, T., and Fischer, T. (2011). The triplet state of organo-transition metal compounds. Triplet harvesting and singlet harvesting for efficient OLEDs. Coord. Chem. Rev. 255, 2622-2652. doi: 10.1016/j.ccr.2011.01.042

Yeung, K.-T., To, W.-P., Sun, C., Cheng, G., Ma, C., Tong, G. S. M., et al. (2017). Luminescent tungsten(VI) complexes: photophysics and applicability to organic light-emitting diodes and photocatalysis. Angew. Chem. Int. Ed. 56, 133-137 doi: 10.1002/anie.201608240

Zhang, J., Duan, C., Han, C., Yang, H., Wei, Y., and Xu, H. (2016), Balanced dual emissions from tridentate phosphine-coordinate copper(I) complexes toward highly efficient yellow OLEDs. Adv. Mater. 28, 5975-5979. doi: 10.1002/adma.201600487

Zhang, Q., Komino, T., Huang, S., Matsunami, S., Goushi, K., and Adachi, C. (2012). Triplet exciton confinement in green organic light-emitting diodes containing luminescent charge-transfer $\mathrm{Cu}(\mathrm{I})$ complexes. Adv. Funct. Mat. 22, 2327-2336. doi: 10.1002/adfm.201101907

Zhou, D., To, W.-P., Kwak, Y., Cho, Y., Cheng, G., Tong, G. S. M., et al. (2019). Thermally stable donor-acceptor type (alkynyl)gold(III) TADF emitters achieved EQEs and luminance of up to $23.4 \%$ and $70300 \mathrm{~cd} \mathrm{~m}^{-2}$ in vacuum-deposited OLEDs. Adv. Sci. 2019:1802297. doi: 10.1002/advs.201 802297

Zhou, D., To, W.-P., Tong, G. S. M., Cheng, G., Du, L., Phillips, D. L., et al. (2020) Tetradentate gold(III) complexes as thermally activated delayed fluorescence (TADF) emitters: microwave-assisted synthesis and high-performance OLEDs with long operational lifetime. Angew. Chem. Int. Ed. 59, 6375-6382. doi: 10.1002/anie.201914661

Zhu, Z.-Q., Fleetham, T., Turner, E., and Li, J. (2015). Harvesting all electrogenerated excitons through metal assisted delayed fluorescent materials. Adv. Mater. 27, 2533-2537. doi: 10.1002/adma.201401772

Conflict of Interest: The authors declare that the research was conducted in the absence of any commercial or financial relationships that could be construed as a potential conflict of interest.

Copyright (c) 2020 To, Cheng, Tong, Zhou and Che. This is an open-access article distributed under the terms of the Creative Commons Attribution License (CC BY). The use, distribution or reproduction in other forums is permitted, provided the original author(s) and the copyright owner(s) are credited and that the original publication in this journal is cited, in accordance with accepted academic practice. No use, distribution or reproduction is permitted which does not comply with these terms. 